\title{
Species specific Beta-D glucan levels at the time of candidemia
}

\author{
Joveria Farooqi, Faisal Malik, Seema Irfan, Afia Zafar, Kauser Jabeen \\ Department of Pathology and Laboratory Medicine, Section of Clinical Microbiology, Aga Khan University, \\ Karachi, Pakistan
}

\section{Objectives}

- Beta-D glucan levels are increasingly being used for early detection of candidemia

- Different fungi have different amounts of BDG in their cell walls. It would be useful to know whether the species causing candidemia differ with respect to the amount of BDG released in circulation.

- Here we analyze the levels of beta D glucan (BDG) specific to different candida species at the time when the patient was candidemic.

- Our second objective was to determine whether BDG levels in $C$. auris candidemia differed from those in non- $C$. auris candidemia

\section{Methods}

- Aga Khan University Clinical Laboratory records from Jan 2015-Dec 2016 were retrospectively reviewed for blood cultures positive for Candida species.

- A total of 149,040 blood cultures were sent from patients registered with AKU Hospital. Of these, 402 $(0.27 \%)$ were positive for Candida species.

- After removing duplicates, 286 episodes of candidemia were identified, of which only $\mathbf{3 9}$ had a concomitant BDG level tested within 5 days before to 14 days after candida was isolated from blood culture (i.e. -5 to +14 days of candidemia). Thus, only these BDG levels were considered representative of the candidemia episode. $(1,2)$

- Most Candida species were identified using API 20C AUX (bioMérieux, France) and colony and microscopic morphology.

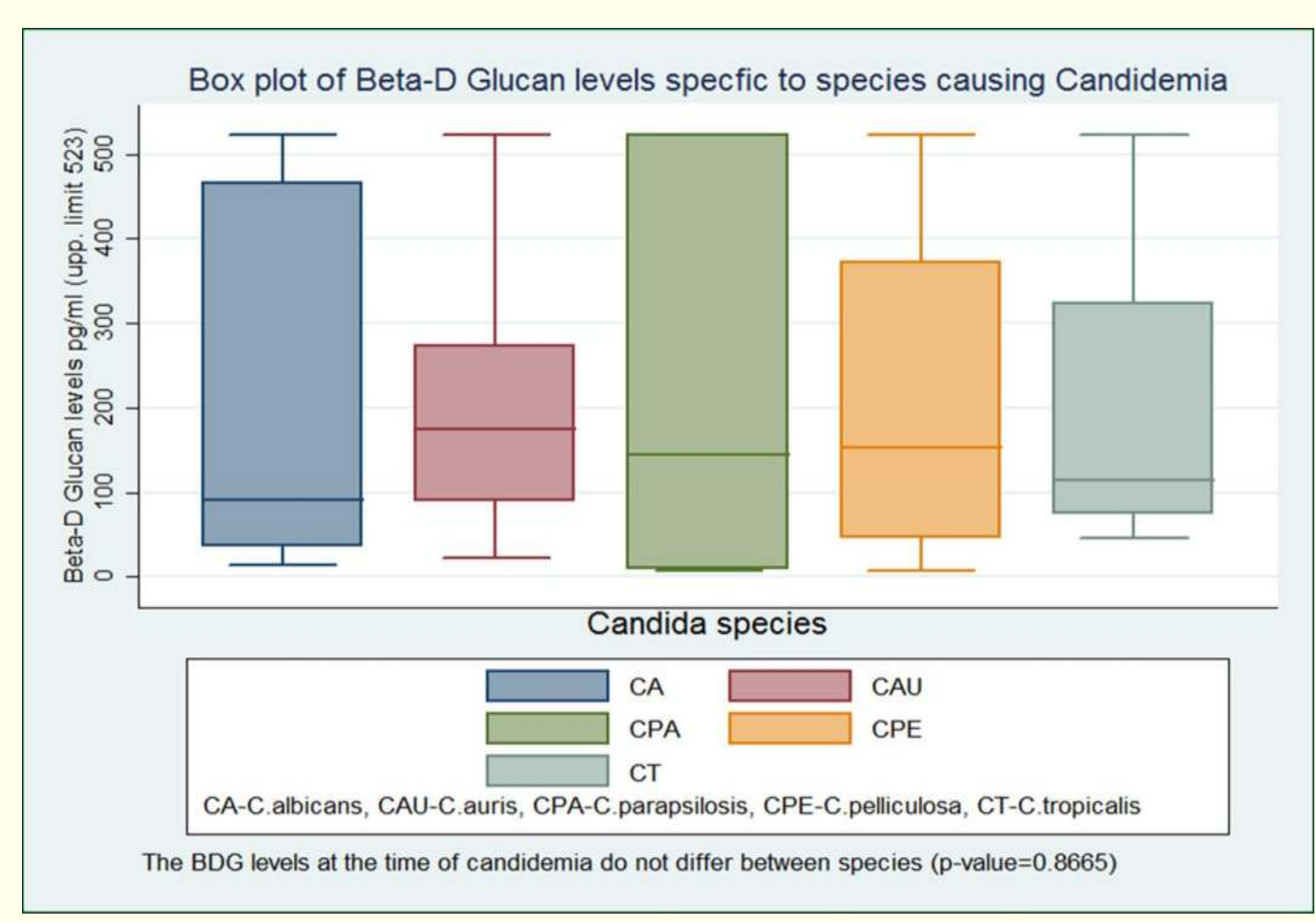

Table: Species-specific mean beta-D glucan levels determined in patient sera within $(-5$ to +14$)$ days of candidemia

\begin{tabular}{|c|c|c|c|c|}
\hline Species & $\begin{array}{l}\text { Frequenc } \\
\text { y }\end{array}$ & $\begin{array}{l}\text { BDG pg/ml } \\
\text { mean (SD) }\end{array}$ & Species (n) & $\begin{array}{l}\text { BDG pg/ml } \\
\text { Mean }(95 \% \mathrm{Cl})\end{array}$ \\
\hline Candida auris & 8 & $202.4(157.7)$ & Candida auris (8) & $202.4(145.7-298.9)$ \\
\hline C. parapsilosis & 11 & $209.7(227.2)$ & \multirow{6}{*}{$\begin{array}{l}\text { Non-C. auris } \\
\text { Candida species } \\
\text { (31) }\end{array}$} & \multirow[t]{6}{*}{$222.3(70.6-334.2)$} \\
\hline C. albicans & 9 & $224.7(221.5)$ & & \\
\hline C. tropicalis & 5 & $215.9(203.6)$ & & \\
\hline C. pelliculosa & 4 & $209.5(227.2)$ & & \\
\hline C. Iusitaniae & 1 & $523.4(-)$ & & \\
\hline C. guilliermondii & 1 & $120.6(-)$ & & \\
\hline \multicolumn{3}{|c|}{ No difference in groups detected (ANOVA $p=0.867$ ) } & \multicolumn{2}{|c|}{$\begin{array}{l}\text { No difference in groups detected (t-test } \\
p=0.250)\end{array}$} \\
\hline
\end{tabular}

References:

1. Posteraro et al. Early diagnosis of candidemia in intensive care unit patients with sepsis: a prospective comparison of (1®3)-b-D-glucan assay, Candida score, and colonization index. Critical Care 2011, 15:R249

2. Presterl et al. Invasive fungal infections and (1,3)-b-D-glucan serum concentrations in long-term intensive care patients. IJID 2009;13:707-712

3. CDC. Recommendations for Identification of Candida auris | Candida ... - CDC. URL: https://www.cdc.gov/fungal/candida-auris/recommendations.html 